\title{
Spatial and morphological change on Eliot Glacier, Mount Hood, Oregon, USA
}

\author{
Keith M. JACKSON, ${ }^{1}$ Andrew G. FOUNTAIN ${ }^{2}$ \\ ${ }^{1}$ Department of Geography, Portland State University, PO Box 751, Portland, OR 97207-0751, USA \\ E-mail: kjack@pdx.edu \\ ${ }^{2}$ Departments of Geology and Geography, Portland State University, PO Box 751, Portland, OR 97207-0751, USA
}

\begin{abstract}
Eliot Glacier is a small $\left(1.6 \mathrm{~km}^{2}\right)$ glacier on Mount Hood, Oregon, USA, and its ablation zone is largely covered with rock debris. We examine the interrelated processes of ablation rates, ice thickness and surface velocities to understand the retreat rate of this glacier. Since measurements began in 1901, the glacier has retreated $680 \mathrm{~m}$, lost $19 \%$ of its area and thinned by about $50 \mathrm{~m}$ at the lower glacier profile before the terminus retreated past that point. The upper profile, $800 \mathrm{~m}$ up-glacier, has shown thinning and thickening due to a kinematic wave resulting from a cool period during the $1940 \mathrm{~s}-70 \mathrm{~s}$, and is currently about the same thickness as in 1940 . Overall, the glacier has retreated at a slower rate than other glaciers on Mount Hood. We hypothesize that the rock debris covering the ablation zone reduces Eliot Glacier's sensitivity to global warming and slows its retreat rate compared to other glaciers on Mount Hood. Spatial variations in debris thickness are the primary factor in controlling spatial variations in melt. A continuity model of debris thickness shows the rate of debris thickening down-glacier is roughly constant and is a result of the compensating effects of strain thickening and debris melt-out from the ice.
\end{abstract}

\section{INTRODUCTION}

Much of the research concerning alpine glaciers has focused on 'clean' glaciers largely devoid of rock debris (Paterson, 1994). While increased attention has recently focused on debris-covered glacier research (e.g. Nakawo and others, 2000), there are still comparatively few studies about the processes and effects of climate change on debris-covered glaciers. Such glaciers are relatively common on the stratovolcanoes of the western United States (Nylen,

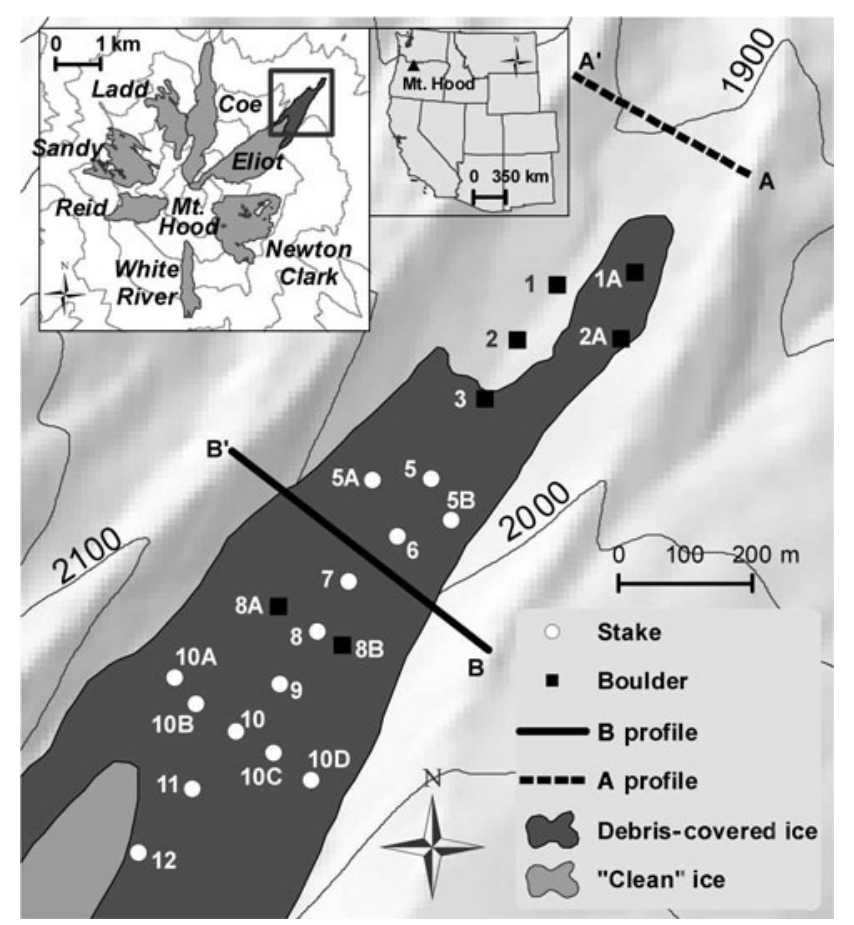

Fig. 1. Map of Eliot Glacier showing measurement locations and elevation profiles.
2004), in the Rocky Mountains (Konrad and Humphrey, 2000), the Hindu Kush-Himalaya region of central Asia (Iwata and others, 2000) and the Andes of South America (Corte, 1998). Our study examines the interrelated morphological processes of changing surface topography on Eliot Glacier, including ice flow, ablation, debris thickness and glacier thinning. Additionally, the spatial change of Eliot Glacier is documented since 1901 relative to six other glaciers on Mount Hood.

\section{STUDY SITE}

Eliot Glacier is a small alpine glacier $\left(\sim 1.6 \mathrm{~km}^{2}\right)$ located on the northeast side of Mount Hood, Oregon, USA (Fig. 1). It descends from a steep headwall of geothermally altered rock, which is mechanically weak and prone to occasional rock avalanches (Lundstrom, 1992). In addition, the adjacent Cooper Spur is composed of block and ash flows and provides another debris source to the eastern portion of the glacier (Crandell, 1980). As a result, the lower portion of Eliot Glacier and much of the ablation zone, $\sim 27 \%$ of the total area, is covered with rock debris. The debris thickens with decreasing elevation: 'clean' ice at $2120 \mathrm{~m}$ and over $1.5 \mathrm{~m}$ thick debris at the terminus (Lundstrom, 1992). The debris cover reduces ablation significantly and is an important factor in glacier mass balance (Conway and Rasmussen, 2000; Kayastha and others, 2000). Debris is only found on two other glaciers on Mount Hood: Coe $(23 \%$ of the total area) and Ladd (41\%).

Eliot Glacier was first photographed in 1901 (Reid, 1905), and these four photographs were used as a baseline for studies in the 1920s and 1930s (Marshall and others, 1925; Phillips, 1938). Detailed measurements of melt, surface elevation and velocities began in 1940. Elevation measurements along two transverse profiles (A and B) showed the glacier thinned from 1940 to 1956 (Dodge, 1964). Dodge (1964) described an 'ice wave' in 1958, which is a 

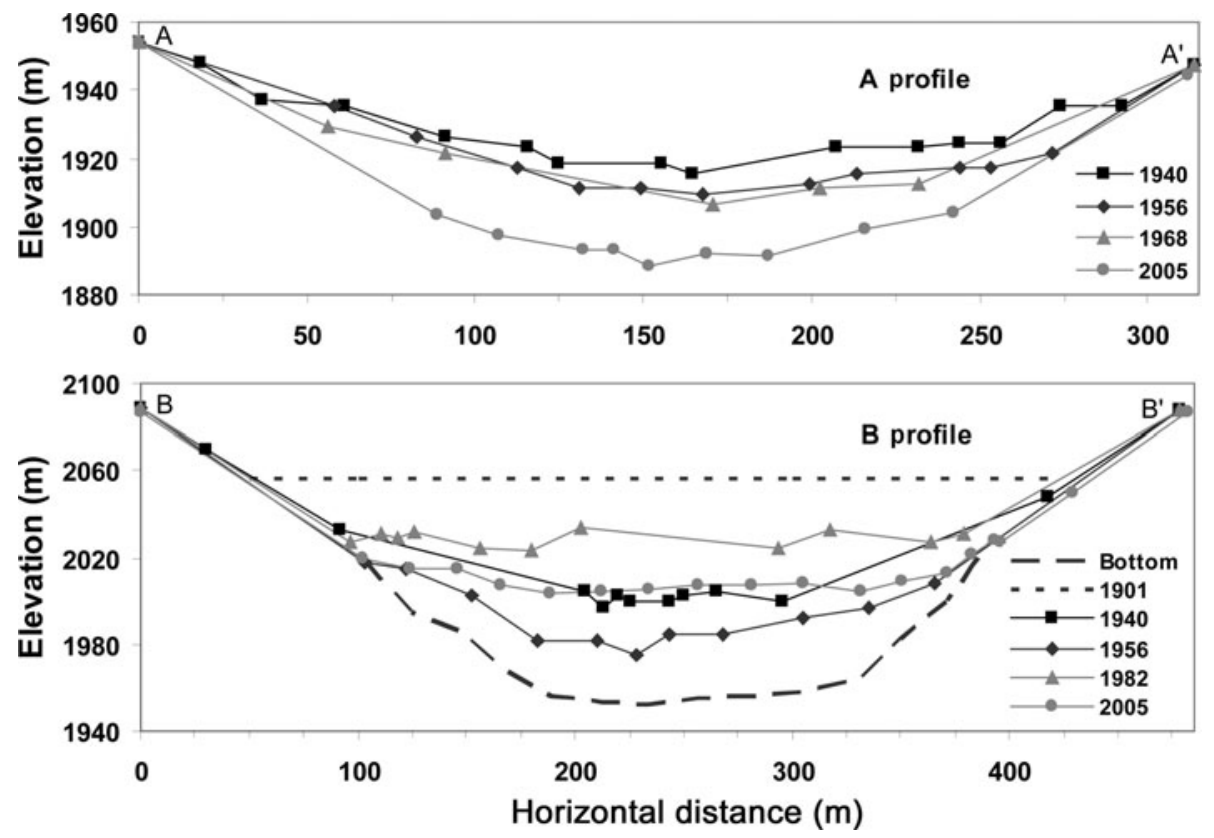

Fig. 2. Elevation profiles on Eliot Glacier. The scales are different between the two plots, but both represent no vertical exaggeration.

kinematic wave (Meier, 1962) and was a response to the positive mass balance (Dodge, 1971). From 1956 to 1982, when the upper profile was last surveyed, the glacier thickened by $50 \mathrm{~m}$ (Dodge, 1987). Surface velocities along the center line decreased from $3.5 \mathrm{~m} \mathrm{a}^{-1}$ at the $\mathrm{B}$ profile (Fig. 1) in the early $1940 \mathrm{~s}$ to $1.4 \mathrm{ma}^{-1}$, prior to the wave, then accelerated to $6.9 \mathrm{~m} \mathrm{a}^{-1}$ in the late $1950 \mathrm{~s}$ and the $1980 \mathrm{~s}$ during the wave (Matthes and Phillips, 1943; Dodge, 1964; Lundstrom, 1992). Eliot Glacier retreated from 1901 to 1959, when the last measurements of terminus location were made. We remeasured the terminus location and measured debris thickness, ice ablation rate and glacier velocity for comparison against Lundstrom's (1992) measurements in the 1980s.

\section{METHODS}

Fourteen plastic (PVC) stakes were drilled into the ice to measure surface displacement and ice ablation (Fig. 1). Only one stake was drilled into clean ice, and the others were covered with $<90 \mathrm{~cm}$ of rock debris. Ablation was measured on a near-daily basis during the summer between 13 August and 24 September 2004, and displacement was measured weekly. All stakes were measured again for ablation and displacement a year later on 28 July 2005. Seven boulders were also surveyed for movement. The transverse elevation profiles (Dodge, 1964) were also remeasured. Although only one of the four end points was still marked, the missing end points were re-established and, we believe, close to the original locations (Jackson, 2007). The profiles and stake locations were surveyed using a conventional total station. Additionally, we conducted a radar survey of glacier depth within the debris-covered area.

Area and length changes on seven of Mount Hood's glaciers were compiled in a geographic information system (GIS) based on maps and historic terrestrial and aerial photographs. These sources date from 1901 to 2004. We calculated buffers around the glacier perimeters to define the uncertainty in area. Root-mean-square errors (rmse) for georeferenced aerial photographs range from 3.6 to $9.6 \mathrm{~m}$, while buffers were defined at $20 \mathrm{~m}$ for ground-based photographs and $15 \mathrm{~m}$ for oblique aerial photographs. Details of the field and analytical methods can be found in Jackson (2007).

\section{RESULTS}

In general, the debris cover thickens down-glacier from the uppermost stake, 12, and towards the sides of the glacier as one would expect from headwall sources and englacial transport. Mass wasting from the large Little Ice Age lateral moraines also contributes to the debris along the lateral margins (Lundstrom, 1992). Along the center line, ablation rates decrease down-glacier and laterally from the center line. At the clean ice the ablation rate was $3.81 \mathrm{ma}^{-1}$, decreasing to $1.23 \mathrm{~m} \mathrm{a}^{-1}$ at the B-profile, $30 \mathrm{~cm}$ debris layer, and to $0.31 \mathrm{~m} \mathrm{a}^{-1} 150 \mathrm{~m}$ down-glacier from $\mathrm{B}$ where the debris is $47 \mathrm{~cm}$ thick.

Since initial measurements in 1940, the glacier has retreated and thinned. The lower (A) profile, which once spanned the glacier, now spans the valley floor (possibly stagnant ice) $350 \mathrm{~m}$ down-valley of the terminus (Fig. 1). If stagnant ice exists it is covered by $>2 \mathrm{~m}$ of debris, as we discovered when attempting to dig to the ice surface. Unfortunately, this area was not included in our groundpenetrating radar (GPR) survey. At the B profile, we estimate the 1901 surface elevation from historic photographs (H.F. Reid) at about $2053 \mathrm{~m}$, suggesting local ice thickness was $\sim 105 \mathrm{~m}$ (Fig. 2). The current glacier elevation at B is $\sim 2000 \mathrm{~m}$ and is remarkably close to that in 1940, suggesting a local ice thickness of $52 \mathrm{~m}$. From 1982 to 2004 the glacier thinned $15-30 \mathrm{~m}$ (average rate $1.0 \mathrm{~m} \mathrm{a}^{-1}$ ), returning to its 1940 elevation.

In general, surface velocities decrease down-glacier and laterally away from the center line, as expected. Velocities were highest at the uppermost stake (stake 12) with $1.17 \pm 0.06 \mathrm{~m}$ of displacement over the 6 week study period $\left(2.8 \pm 0.1 \mathrm{~cm} \mathrm{~d}^{-1}\right)$ and $7.52 \pm 0.03 \mathrm{~m}$ over the 350 day study 

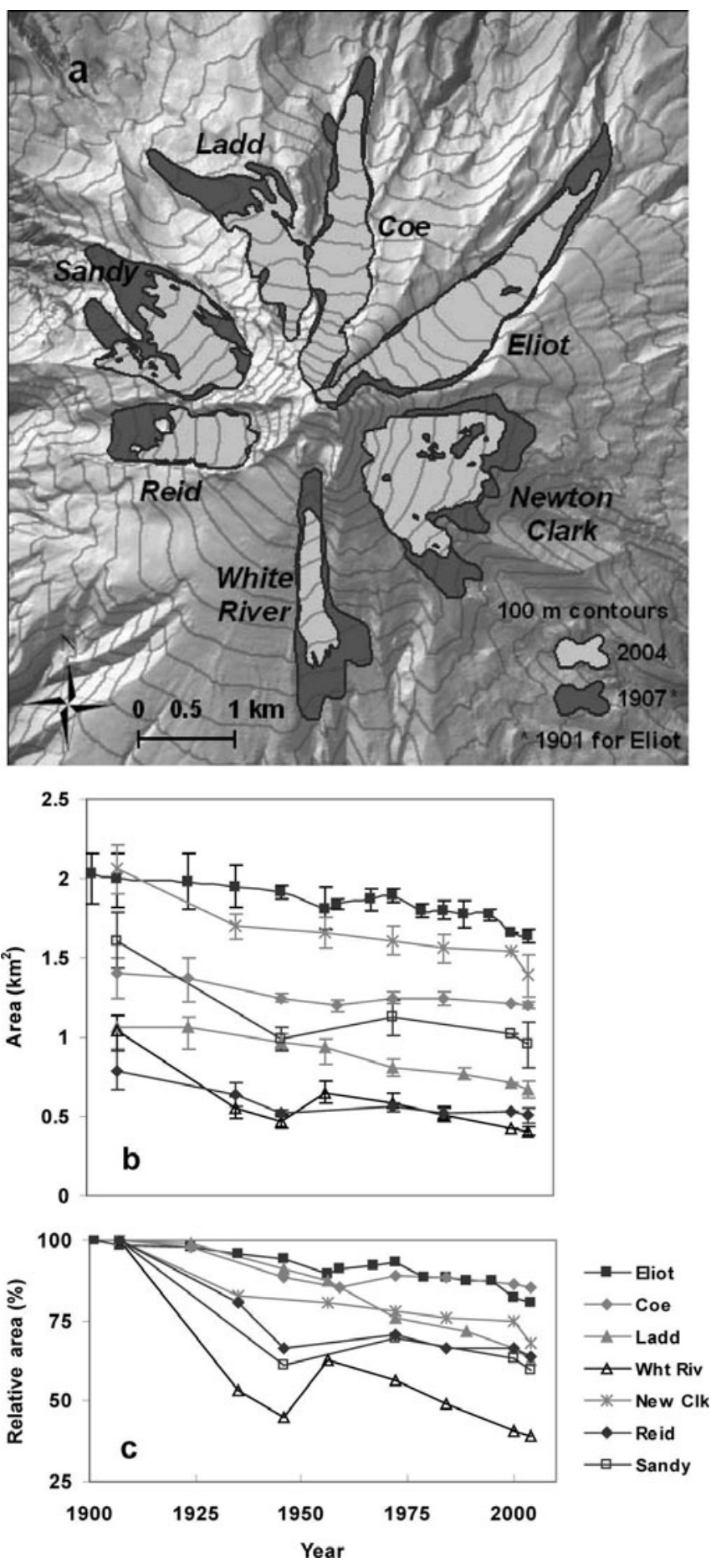

Fig. 3. Change on seven of Mount Hood's glaciers over the 20th century: (a) map of areal change, 1907-2004; (b) area change with time for individual glaciers; and (c) fractional area change.

period $\left(7.85 \pm 0.03 \mathrm{~m} \mathrm{a}^{-1}\right)$. Velocities decreased to near zero at the lowest boulders (boulders 1, 2, 1A and 2A in Fig. 1).

The area of Eliot Glacier in 1901 was $2.03 \pm 0.16 \mathrm{~km}^{2}$ and decreased to $1.60 \pm 0.05 \mathrm{~km}^{2}$ by $2004(-19 \%)$, resulting in a terminus retreat of $680 \mathrm{~m}$ (Fig. 3a). During this 103 year period, glacier area decreased until 1956, when it increased until the early 1970 s and started to decrease again. The most pronounced shrinkage has occurred since 1995, with a loss of $0.14 \mathrm{~km}^{2}$ from 1995 to 2004 . In comparison, the other six glaciers on Mount Hood exhibit similar patterns, retreating through the first half of the 20th century, advancing or at
Table 1. Area and length change on the seven Mount Hood glaciers examined

\begin{tabular}{lccccc}
\hline Glacier & 1907 area & 2004 area & Loss & $\begin{array}{c}\text { Loss } \\
\text { (T) }\end{array}$ & $\begin{array}{c}\text { Terminus } \\
\text { retreat }\end{array}$ \\
& $\mathrm{km}^{2}$ & $\mathrm{~km}^{2}$ & $\mathrm{~km}^{2}$ & $\%$ & $\mathrm{~m}$ \\
\hline Coe & $1.41 \pm 0.13$ & $1.20 \pm 0.02$ & 0.21 & 15 & 390 \\
Eliot* & $2.03 \pm 0.16$ & $1.64 \pm 0.05$ & 0.39 & 19 & 680 \\
Ladd & $1.07 \pm 0.10$ & $0.67 \pm 0.05$ & 0.40 & 37 & 1190 \\
Newton Clark & $2.06 \pm 0.15$ & $1.40 \pm 0.14$ & 0.66 & 32 & 310 \\
Reid & $0.79 \pm 0.13$ & $0.51 \pm 0.05$ & 0.28 & 35 & 490 \\
Sandy & $1.61 \pm 0.17$ & $0.96 \pm 0.14$ & 0.65 & 40 & 690 \\
White River & $1.04 \pm 0.11$ & $0.41 \pm 0.03$ & 0.63 & 61 & 510 \\
Total & $10.01 \pm 0.36$ & $6.79 \pm 0.22$ & 3.22 & - & - \\
Average & $1.43 \pm 0.14$ & $0.97 \pm 0.07$ & 0.46 & 34 & 609 \\
& & & & & \\
\hline
\end{tabular}

*1901 for Eliot Glacier rather than 1907.

least slowing their retreat dramatically in the 1960s and 1970s, and then retreating again. Proportionally, Coe Glacier lost the least area, 15\%, while White River Glacier lost the most, $61 \%$. The ice-covered area loss of the seven glaciers was $34 \%$ (Table 1 ).

\section{ANALYSIS AND DISCUSSION}

The spatial and morphological changes of Eliot Glacier over the past 104 years are a reflection of the climate of Mount Hood. Average summer temperatures (5 year running averages) on Mount Hood increased from $5.6^{\circ} \mathrm{C}$ in 1902 to $8.8^{\circ} \mathrm{C}$ in 2002 (Daly and others, 1997), whereas no overall trend in winter precipitation is observed. From 1900 through 1940, summer temperatures warmed and winter precipitation was low, generally resulting in glacier recession and thinning (Fig. 4). From the 1950s to the 1970s, temperatures cooled and precipitation increased, resulting in glacier advance or slowing of retreat. Since the mid-1970s, air temperature has increased and precipitation decreased, resulting in further recession and thinning.

Ablation rates have changed on the glacier. At the B profile, the ablation rate was $1.95 \mathrm{~m} \mathrm{a}^{-1}$ in the early $1940 \mathrm{~s}$ (Matthes and Phillips, 1943), dropping to $1.08 \mathrm{~m} \mathrm{a}^{-1}$ between 1940 and 1956 (Handewith, 1959), and increasing to $1.23 \mathrm{~m} \mathrm{a}^{-1}$ currently. Daily values of summer ablation near the B profile in 1988-89 were about $0.24 \mathrm{~cm} \mathrm{~d}^{-1}$ (Lundstrom, 1992), while our data show about $0.33 \mathrm{~cm} \mathrm{~d}^{-1}$. The average thinning rate from 1984 to 1989 over the debris-covered portion of the glacier was $0.8 \mathrm{~m} \mathrm{a}^{-1}$ (Lundstrom and others, 1993), whereas the current rate from 1989 to 2004 is $1 \mathrm{~m} \mathrm{a}^{-1}$. Mean monthly temperatures on Mount Hood show mean summer (July-September) temperatures during Lundstrom's study were $9.6^{\circ} \mathrm{C}$, while during ours they were $11.5^{\circ} \mathrm{C}$. Clearly the summer air temperature has increased by almost $2{ }^{\circ} \mathrm{C}$ since the Lundstrom study, yet the ablation rate increased by only about $0.1 \mathrm{~cm} \mathrm{~d}^{-1}$. We hypothesize that as the debris cover thickens, the insulating effects are increased, partly offsetting the ablation effects of atmospheric warming. A statistical examination of ablation rates with debris thickness and local temperature demonstrates that debris cover has a greater effect on ablation than does adiabatically dependent summer temperature, with debris thickness explaining $64 \%$ of the variance in ablation rates. Additionally, 
regression analyses show significant effects on ablation by debris cover $\left(R^{2}=0.40, p=0.01\right)$, whereas effects by temperature are not significant $\left(R^{2}=0.23, p=0.09\right)$.

To estimate the rate of debris thickening over time, we apply a one-dimensional continuity equation (equation (2) in Lundstrom and others, 1993)

$$
\frac{\partial S}{\partial t}=-S \nabla v-\frac{\dot{b} C}{(1-\Phi)}+D,
$$

where $S$ is the debris thickness $(\mathrm{m}), \nabla v$ is the horizontal strain rate $\left(\mathrm{a}^{-1}\right), \dot{b}$ is the net ice mass balance $\left(\mathrm{m} \mathrm{a}^{-1}\right), C$ is the englacial volumetric concentration of debris (unitless), $\Phi$ is the porosity of supraglacial debris (unitless) and $D$ is subaerial deposition rate of debris $\left(\mathrm{m} \mathrm{a}^{-1}\right)$. The first term on the lefthand side is the debris thickness change with time, the first term on the righthand side is the thickness change as a result of longitudinal ice strain, and the second term on the righthand side is the rate of debris melting out from the glacier. We assume no loss of debris and no direct contribution of debris through rock avalanches local to the ablation zone because no evidence for them exists and aeolian input is insignificant (Lundstrom, 1992). Results show that the strain thickening of the debris increases downglacier and the rate of debris melt-out decreases. Together, these two processes compensate, resulting in a spatially constant debris supply over the ablation zone of $5 \mathrm{~mm} \mathrm{a}^{-1}$. At the uppermost stake segments, where debris is $\sim 6 \mathrm{~cm}$ thick, strain thickening accounts for roughly $7 \%$ of the thickening, and melt-out accounts for the remaining 93\%. At the lowermost stake segments, where the debris is $\sim 70 \mathrm{~cm}$ thick, strain accounts for $82 \%$ of the debris thickening and melt-out contributes only $18 \%$. Predictive estimates of debris thickness along the glacier's center line suggest $30 \mathrm{~cm}$ of debris at the B profile, close to the actual value of $32 \mathrm{~cm}$. Overall, a correlation of 0.93 exists between field data and model results. Over the $\sim 15$ year interval between Lundstrom's study and ours, we estimate the debris layer thickened by $\sim 7.5 \mathrm{~cm}$, which dramatically slows ablation rates for originally thin $(\sim 3 \mathrm{~cm})$ debris covers and significantly slows thicker covers $(\sim 40 \mathrm{~cm})$. Therefore we regard the thickening of debris as an important factor in buffering the glacier mass-balance response to climate warming.

Eliot Glacier continues to thin, however, and the increasing debris thickness only partly buffers the effects of climate warming. Consequently, we infer that the thinning rate would be greater without the debris cover. Because of the insulating effects of the debris cover, we expect the glacier to respond more to changes in mass input to the glacier than to changes in mass loss through melting. We have seen evidence of a sensitive response to a period of positive mass balance that resulted in the initiation of a kinematic wave and thickening of the glacier. That the current surface elevation of the B profile is only now at the 1940 pre-wave elevation points to the reduced effect of ablation caused by the presence of the debris cover. However, the rate of debris thickening is not keeping pace with the rate of climate warming, and the glacier is accelerating its retreat. It would be tempting to explain the relatively small shrinkage of Eliot and Coe Glaciers compared to other glaciers on Mount Hood solely in terms of a thickening of the debris layer (Fig. 3c). However, other mitigating factors exist. Both Eliot and Coe have the highest accumulation zones, which head near the peak of Mount Hood $(3425 \mathrm{~m})$. Therefore, rising freezing levels and
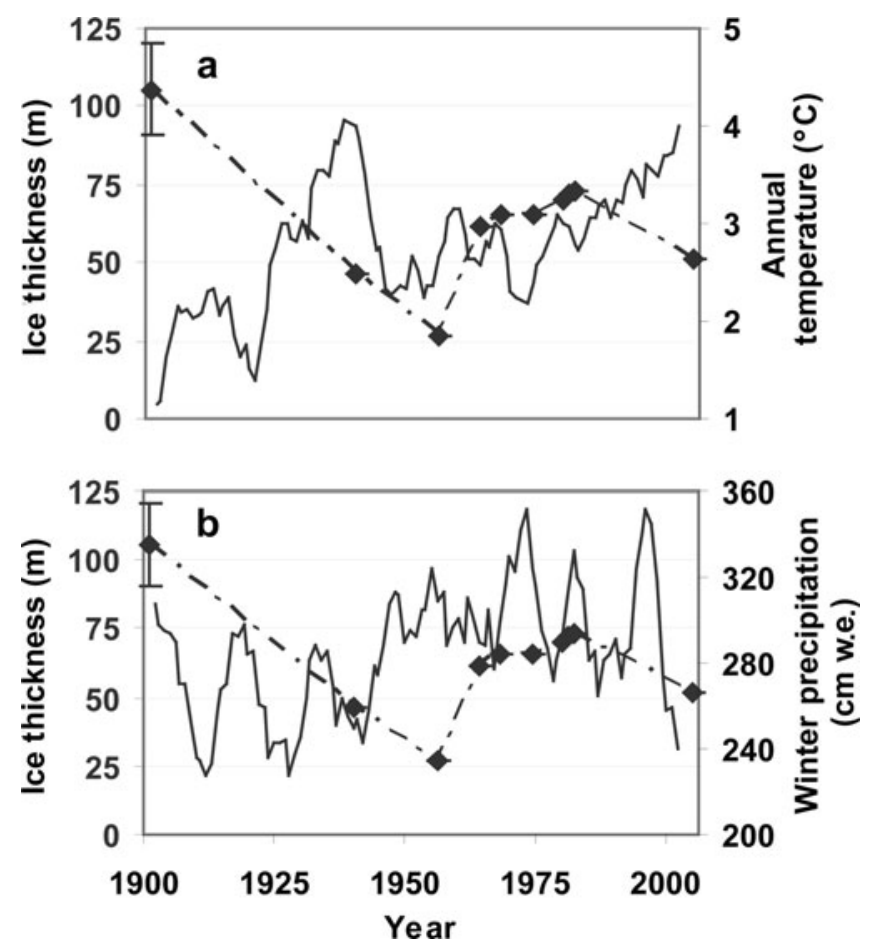

Fig. 4. Ice thickness at the B profile (dashed line) plotted with a 5 year running average annual temperature (a) and winter precipitation (b) (Daly and others, 1997).

snowlines have not affected these glaciers as much as the other glaciers, which have a smaller elevation range. Aspect is likely another factor, as Eliot and Coe are the most northerly-flowing glaciers on the mountain. These factors have also been documented on Mount Rainier, Washington, USA (Nylen, 2004). It is worth mentioning Ladd Glacier's large retreat despite its high debris cover and northwest aspect. A low accumulation area and a unique low slope near its terminus may have accelerated glacial loss. Overall, the changes exhibited on Mount Hood since 1901 are similar to glacier variations elsewhere in the American West (e.g. Marston and others, 1991; Key and others, 2002; Nylen, 2004; Granshaw and Fountain, 2006; Hoffman and others, 2007).

\section{ACKNOWLEDGEMENTS}

This work was supported by the Geological Society of America, the Mazamas Research Committee, Sigma Xi, NASA grant NNGO4GJ41G and US National Science Foundation grant BCS-0351004. W. Pattison and the Crag Rats Cloud Cap Inn cabin on Mount Hood provided excellent facilities that facilitated this project. We especially thank H. Basagic, F. Granshaw, T. Nylen, R. Pettersson, R. Robb, R. Schlichting and P. Sniffen for help in the field.

\section{REFERENCES}

Conway, H. and L.A. Rasmussen. 2000. Summer temperature profiles within supraglacial debris on Khumbu Glacier Nepal. IAHS Publ. 264 (Workshop at Seattle 2000 - Debris-Covered Glaciers), 89-97.

Corte, A.E. 1998. Rock glaciers. In Williams, R.S., Jr and J.G. Ferrigno, eds. Satellite image atlas of glaciers of the world. US Geol. Surv. Prof. Pap. 1386-I, I136-I141. 
Crandell, D.R. 1980. Recent eruptive history of Mount Hood, Oregon, and potential hazards from future eruptions. USGS Bull. 1492.

Daly, C., G. Taylor and W. Gibson. 1997. The PRISM approach to mapping precipitation and temperature. In Proceedings of the 10th Conference on Applied Climatology, 20-23 October 1997, Reno, Nevada. Boston, MA, American Meteorological Society, 208-209.

Dodge, N.A. 1964. Recent measurements on the Eliot Glacier. Mazama, 46(13), 47-49.

Dodge, N.A. 1971. The Eliot Glacier: new methods and some interpretations. Mazama, 53(13), 25-29.

Dodge, N.A. 1987. Eliot Glacier: net mass balance. Mazama, 69(13), 52-55.

Granshaw, F.D. and A.G. Fountain. 2006. Glacier change (19581998) in the North Cascades National Park Complex, Washington, USA. J. Glaciol., 52(177), 251-256.

Handewith, H. 1959. Recent glacier variations on Mt. Hood. Mazama, 40(14), 23-28.

Hoffman, M.J., A.G. Fountain and J.M. Achuff. 2007. 20th-century variations in area of small glaciers and ice fields, Rocky Mountain National Park, Rocky Mountains, Colorado, USA. Ann. Glaciol., 46 (see paper in this volume).

Iwata, S., T. Aoki, T. Kadota, K. Seko and S. Yamaguchi. 2000. Morphological evolution of the debris cover on Khumbu Glacier, Nepal, between 1978 and 1995. IAHS Publ. 264 (Workshop at Seattle, 2000 - Debris-Covered Glaciers), 3-11.

Jackson, K.M. 2007. Spatial and morphological change on Eliot Glacier, Mount Hood. (MS thesis, Portland State University.)

Kayastha, R.B., Y. Takeuchi, M. Nakawo, and Y. Ageta. 2000. Practical prediction of ice melting beneath various thickness of debris cover on Khumbu Glacier, Nepal using a positive degreeday factor. IAHS Publ. 264 (Workshop at Seattle 2000 - DebrisCovered Glaciers), 71-81.
Key, C.H., D.B. Fagre and R.K. Menicke. 2002. Glacier retreat in Glacier National Park, Montana. In Williams, R.S., Jr and J.G. Ferrigno, eds. Satellite image atlas of glaciers of the world. US Geol. Surv. Prof. Pap. 1386-J, J365-J375.

Konrad, S.K. and N.F. Humphrey. 2000. Steady-state flow model of debris-covered glaciers (rock glaciers). IAHS Publ. 264 (Workshop at Seattle 2000 - Debris-Covered Glaciers), 255-263.

Lundstrom, S.C. 1992. The budget and effect of superglacial debris on Eliot Glacier, Mount Hood, Oregon. (PhD thesis, University of Colorado.)

Lundstrom, S.C., A.E. McCafferty and J.A. Coe. 1993. Photogrammetric analysis of 1984-89 surface altitude change of the partially debris-covered Eliot Glacier, Mount Hood, Oregon, U.S.A. Ann. Glaciol., 17, 167-170.

Marshall, E.A. and 6 others. 1925. First annual report of the research committee. Mazama, 7(2), 67-72.

Marston, R.A., L.O. Pochop, G.L. Kerr, M.L. Varuska and D.I. Veryzer. 1991. Recent glacier changes in the Wind River Range, Wyoming. Phys. Geogr., 12(2), 115-123.

Matthes, F.E. and K.N. Phillips. 1943. Surface ablation and movement of the ice on Eliot Glacier. Mazama, 25(12), 17-23.

Meier, M.F. 1962. The kinematic wave on Nisqually Glacier, Washington. J. Geophys. Res., 67(2), 886.

Nakawo, M., C.F. Raymond and A. Fountain, eds. 2000. IAHS Publ. 264 (Workshop at Seattle 2000 - Debris-Covered Glaciers).

Nylen, T.N. 2004. Spatial and temporal variations of glaciers on Mount Rainier between 1913 and 1994. (MS thesis, Portland State University.)

Paterson, W.S.B. 1994. The physics of glaciers. Third edition. Oxford, etc., Elsevier.

Phillips, K.N. 1938. Our vanishing glaciers: observations by the Mazama Research Committee on glaciers of the Cascade Range, in Oregon. Mazama, 20(12), 24-41

Reid, H.F. 1905. The glaciers of Mt. Hood and Mt. Adams. Mazama, 2(4), 195-200. 